\title{
Statistical Analysis of M-ary FSK over Different Fading Models
}

\author{
Shruti \\ $\left(7^{\text {th }}\right.$ semester,NIT Kurukshetra (India)
}

\begin{abstract}
Statistical analysis of M-ary FSK over different fading models is done. Frequency selective fading is considered and the M ary FSK modulation scheme have been analysed statistically for different models to see their effect on the output of the receiver. The effects of noise and interference are considered along. The paper involves Rayleigh fading model,Nakagami fading model and Weibull fading. The performance results are obtained through MATLAB simulation.
\end{abstract}

Index terms: probability density function, cumulative distribution function, M-ary FSK, Rayleigh Fading,Nakagami Fading, Weibull Fading, intersymbol interference, gaussian noise

\section{Introduction}

In the study of communication systems the classical additive white Gaussian noise(AWGN) channel which consists of statistically independent Gaussian noise samples free of intersymbol interference is the starting point of understanding the basic performance of any system. However,external interference is received by the antenna which turns out to be more significant factor than thermal noise.

The presence of fading,interference and noise at the input of the system affect the system in various ways. The signal may have time varying amplitude or phase which makes signal detection more complicated. In this paper we consider the system of coherent demodulation in the presence of Gaussian noise ,fading and intersymbol interference. These disturbances can seriously degrade the communication systems. Performance analysis of wide-band M-ary FSK system in Rayleigh , Nakagami and Weibull fading is given.

The probability density function of M-ary FSK output signal and its derivative have been derived in order to see the effect of Gaussian noise, intersymbol interference and fading .M-ary FSK system consists of M symbols with $\mathrm{M}$ different frequencies.

The dual branch FSK receiver is considered for the computer simulation of the numerical results because of its easy implementation and very good performances.

\section{M-Ary Fsk System}

In an M-ary FSK system there are M message symbols. Each message symbol is identified by having a different frequency. Therefore, there are $\mathrm{M}$ frequencies corresponding to $\mathrm{M}$ different symbols. The receiver can thus be shown as consisting of $\mathrm{M}$ branches. Each branch consists of a correlator which consists of a multiplier followed by an integrator. Integrator acts as a low pass filter. The signal at the input of the receiver is the FSK modulated signal which is corrupted due to the presence of Gaussian noise, interference and fading.

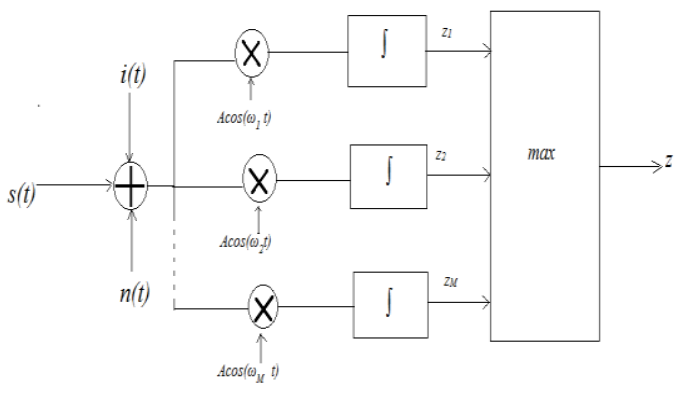

Fig 1: Receiver for coherent demodulation of M-ary FSK signal

considering hypothesis $\mathrm{Hi}$, we can represent the transmitted symbol as

$\mathrm{s}(\mathrm{t})=\mathrm{A} \cos (\omega \mathrm{it}) \quad \ldots(1)$

A here denotes the amplitude of the modulated signal. As we know that in presence of fading, we have variable amplitude. In this paper we are considering Rayleigh distribution, Rice distribution, Nakagami distribution and Weibull distribution.

Gaussian noise at the input of the receiver can be given as: 
$n(t)=\sum_{i=1}^{M}\left(x_{i} \cos (\omega i t)+y_{i} \sin (\omega i t)\right)$

$\mathrm{xi}$ and yi are the components of Gaussian noise with zero means and variances $\sigma^{2}$

Corresponding to the hypothesis $\mathrm{H}_{1}, \mathrm{H}_{2} \ldots \ldots \ldots \ldots \mathrm{H}_{M}$, we have the signals with central frequencies $\omega_{1}, \omega_{2} \ldots \ldots$ $\omega_{M}$. These signals are passed through the correlators to produce the branch outputs $\mathrm{z}_{1}, \mathrm{z}_{2}, \mathrm{z}_{3} \ldots \ldots \ldots \ldots \ldots \ldots \ldots \mathrm{z}_{\mathrm{M}}$. Each correlator consists of a multiplier in which the signal is multiplied with the signal from the local oscillator followed by a low pass filter or integrator.The receiver output is given as :

$\mathrm{z}=\max \left\{\mathrm{z}_{1}, \mathrm{z}_{2}, \mathrm{z}_{3} \ldots \ldots \ldots \ldots \ldots \ldots \mathrm{z}_{\mathrm{M}}\right\}$

Consider the hypothesis $\mathrm{H}_{1}$ the transmitted signal is given as:

$\mathrm{s}(\mathrm{t})=\mathrm{A} \cos \omega_{1} \mathrm{t} \quad$...(3)

Now due to effects of noise and interference,the signal is corrupted. Gaussian noise as stated before is given as:

$n(t)=\sum_{i=1}^{M}\left(x_{i} \cos (\omega i t)+y_{i} \sin (\omega i t)\right)$

The interference $i(t)$ can be shown as:

$i(t)=\sum_{i=1}^{M}\left(A_{i} \cos (\omega i t+\theta i)\right)$

If $\mathrm{i}(\mathrm{t})$ is the pulse interference, that is in the presence of Nakagami fading, it has the distribution given by:

$i(t)=\sum_{i=1}^{M}\left(\left(A_{i}+c n\right) \cos (\omega i t+\theta i)\right)$

$p(n)=\lambda^{n} \frac{e^{-\lambda}}{n !}$

$\lambda$ is intensity of impulse process.

Phases $\theta_{\mathrm{i}}, \mathrm{i}=1,2, \ldots, \mathrm{M}$ have uniform probability density function.

$z(t)$, that is the received signal can be represented as the sum of the original modulated signal $s(t)$, noise $n(t)$ and the interference $i(t)$.

Therefore, we have $\mathrm{z}(\mathrm{t})=\mathrm{s}(\mathrm{t})+\mathrm{n}(\mathrm{t})+\mathrm{i}(\mathrm{t})$

The output branch signals of the receiver are therefore given as:

$z_{1}=\int_{0}^{T} z(t) \cdot \cos \left(z \omega_{1} t\right)$

Putting $z(t)=s(t)+n(t)+i(t)$

$z_{1}=\int_{0}^{T} s(t)+n(t)+i(t) \cdot \cos \left(\omega_{1} t\right)$

As we know that the basis functions are orthonormal and have unit energy, the terms corresponding to the frequency term $\omega_{1}$ appear in the equation for value of $z_{1}$ and all other terms reduces to zero. Therefore taking the term containing the frequency $\omega_{1}$ from the noise term $n(t)$ and the interference term $i(t)$ and reducing all other terms to zero, we could see that

$\mathrm{z}_{1}=\mathrm{A}+\mathrm{x}_{1}+\mathrm{A}_{1} \cos \theta_{1}$

$\mathrm{z}_{2}=\mathrm{x}_{2}+\mathrm{A}_{2} \cos \theta_{2}$

......

$\mathrm{z}_{\mathrm{k}}=\mathrm{x}_{\mathrm{k}}+\mathrm{A}_{\mathrm{k}} \cos \theta_{\mathrm{k}}, \mathrm{k}=2,3, \ldots, \mathrm{M}$

It is necessary to define the probability density functions of the branches output signals and the cumulative density of these signals to obtain probability density function of M-ary FSK receiver output signal. 


\section{Statistical Characteristics While Considering Different Fading Models}

\subsection{Rayleigh Fading:}

In case of Rayleigh fading the amplitude of the received signal varies as

$\frac{\mathrm{A}}{\sigma^{2}} \mathrm{e}^{-\frac{\mathrm{A}^{2}}{2 \sigma^{2}}}$

The conditional probability density functions for the signals $z_{1}, z_{2}, \ldots, z_{M}$, in the presence of impulse interference and Rayleigh fading, are:

$$
\begin{aligned}
& \mathrm{p}_{\mathrm{z}_{1} / \mathrm{A}, \theta_{1}}\left(\mathrm{z}_{1}\right)=\frac{1}{\sigma \sqrt{2 \pi}} \mathrm{e}^{-\frac{\left(\mathrm{z}_{1}-\mathrm{A}-\mathrm{A}_{1} \cos \left(\theta_{1}\right)\right)^{2}}{2 \sigma^{2}}} \ldots \\
& \mathrm{p}_{\mathrm{z}_{2} / \mathrm{A}, \theta_{2}}\left(\mathrm{z}_{2}\right)=\frac{1}{\sigma \sqrt{2 \pi}} \mathrm{e}^{-\frac{\left(\mathrm{z}_{2}-\mathrm{A}_{2} \cos \left(\theta_{2}\right)\right)^{2}}{2 \sigma^{2}}} \ldots( \\
& \ldots \\
& \mathrm{p}_{\mathrm{z}_{\mathrm{k}} / \mathrm{A}, \theta_{\mathrm{k}}}\left(\mathrm{z}_{\mathrm{k}}\right)=\frac{1}{\sigma \sqrt{2 \pi}} \mathrm{e}^{-\frac{\left(\mathrm{z}_{\mathrm{k}}-\mathrm{A}_{\mathrm{k}} \cos \left(\theta_{\mathrm{k}}\right)\right)^{2}}{2 \sigma^{2}} \ldots} \ldots
\end{aligned}
$$

$\mathrm{k}=2,3 \ldots \mathrm{M}$

By averaging the equations 6 to 8 for each $z_{i}$ we could find the probability density functions of the output branch signals.

$\mathrm{p}_{\mathrm{z}_{1}}\left(\mathrm{z}_{1}\right)=\int_{0}^{\infty} \int_{-\pi}^{\pi} \frac{1}{\sigma \sqrt{2 \pi}} \mathrm{e}^{-\frac{\left(\mathrm{z}_{1}-\mathrm{A}-\mathrm{A}_{1} \cos \left(\theta_{1}\right)\right)^{2}}{2 \sigma^{2}}}$

$\frac{\mathrm{A}}{\sigma^{2}} \mathrm{e}^{-\frac{\mathrm{A}^{2}}{2 \sigma^{2}} \mathrm{dA}} \frac{1}{2 \pi} \mathrm{d} \theta_{1}$

$\mathrm{p}_{\mathrm{z}_{2}}\left(\mathrm{z}_{2}\right)=\int_{0}^{\infty} \int_{-\pi}^{\pi} \frac{1}{\sigma \sqrt{2 \pi}} \mathrm{e}^{-\frac{\left(\mathrm{z}_{2}-\mathrm{A}_{2} \cos \left(\theta_{2}\right)\right)^{2}}{2 \sigma^{2}}}$

$\frac{A}{\sigma^{2}} e^{-\frac{A^{2}}{2 \sigma^{2}}} d A \frac{1}{2 \pi} d \theta_{2}$

$\mathrm{p}_{\mathrm{z}_{\mathrm{k}}}\left(\mathrm{z}_{\mathrm{k}}\right)=\int_{0}^{\infty} \int_{-\pi}^{\pi} \frac{1}{\sigma \sqrt{2 \pi}} \mathrm{e}^{-\frac{\left(\mathrm{z}_{\mathrm{k}}-\mathrm{A}_{\mathrm{k}} \cos \left(\theta_{\mathrm{k}}\right)\right)^{2}}{2 \sigma^{2}}}$

$\frac{\mathrm{A}}{\sigma^{2}} \mathrm{e}^{-\frac{\mathrm{A}^{2}}{2 \sigma^{2}}} \mathrm{dA} \frac{1}{2 \pi} \mathrm{d} \theta_{\mathrm{k}}$

The cumulative distribution functions of the signals $\mathrm{z}_{1}, \mathrm{Z}_{2} \ldots . . . \mathrm{Z}_{\mathrm{M}}$ are given as:

$\mathrm{F}_{\mathrm{z}_{1}}\left(\mathrm{z}_{1}\right)=\int_{-\infty}^{\mathrm{z}_{1}} \int_{0}^{\infty} \int_{-\pi}^{\pi} \frac{1}{\sigma \sqrt{2 \pi}} \mathrm{e}^{-\frac{\left(\mathrm{z}_{1}-\mathrm{A}-\mathrm{A}_{1} \cos \left(\theta_{1}\right)\right)^{2}}{2 \sigma^{2}}}$.

$\frac{\mathrm{A}}{\sigma^{2}} \mathrm{e}^{-\frac{\mathrm{A}^{2}}{2 \sigma^{2}}} \mathrm{dA} \frac{1}{2 \pi} \mathrm{d} \theta_{1} \mathrm{dz} \mathrm{z}_{1}$

$\mathrm{F}_{\mathrm{z}_{2}}\left(\mathrm{z}_{2}\right)=\int_{-\infty}^{\mathrm{z}_{2}} \int_{0}^{\infty} \int_{-\pi}^{\pi} \frac{1}{\sigma \sqrt{2 \pi}} \mathrm{e}^{-\frac{\left(\mathrm{z}_{2}-\mathrm{A}_{2} \cos \left(\theta_{2}\right)\right)^{2}}{2 \sigma^{2}}}$.

$\cdot \frac{\mathrm{A}}{\sigma^{2}} \mathrm{e}^{-\frac{\mathrm{A}^{2}}{2 \sigma^{2}}} \mathrm{dA} \frac{1}{2 \pi} \mathrm{d} \theta_{2} \mathrm{dz}$

$\mathrm{F}_{\mathrm{z}_{\mathrm{k}}}\left(\mathrm{z}_{\mathrm{k}}\right)=\int_{-\infty}^{\mathrm{z}_{\mathrm{k}}} \int_{0}^{\infty} \int_{-\pi}^{\pi} \frac{1}{\sigma \sqrt{2 \pi}} \mathrm{e}^{-\frac{\left(\mathrm{z}_{\mathrm{k}}-\mathrm{A}_{\mathrm{k}} \cos \left(\theta_{\mathrm{k}}\right)\right)^{2}}{2 \sigma^{2}}}$

$\cdot \frac{A}{\sigma^{2}} e^{-\frac{A^{2}}{2 \sigma^{2}}} d A \frac{1}{2 \pi} d \theta_{2} d z_{k}$ 
The probability density function of the M-ary FSK receiver output in case of hypothesis $\mathrm{H}_{1}$ can be obtained from the equation:

$p_{z}(z)=\sum_{i=1}^{M} p_{i}(z) \cdot \prod_{\substack{j=1 \\ j \neq i}}^{M} F_{j}(z)$

The joint probability density function of the output and its derivative is given as:

$\mathrm{p}_{\mathrm{z} \dot{\mathrm{z}}}(\mathrm{z}, \dot{\mathrm{z}})=\sum_{\mathrm{i}=1}^{\mathrm{M}} \mathrm{p}_{\mathrm{z}_{\mathrm{i}} \dot{\mathrm{z}}_{\mathrm{i}}}(\mathrm{z}, \dot{\mathrm{z}}) \cdot \prod_{\substack{\mathrm{j}=1 \\ \mathrm{j} \neq \mathrm{i}}}^{\mathrm{M}} \mathrm{F}_{\mathrm{z}_{\mathrm{j}}}(\mathrm{z})$

3.2 Weibull Fading

In this case, the amplitude varies according to the equation given as weibull disitribution:

$\mathrm{p}_{\mathrm{A}}(\mathrm{A})=\frac{\beta}{\Omega} \cdot(\mathrm{A} / \Omega)^{\beta-1} \cdot \mathrm{e}^{(-\mathrm{A} / \Omega)^{\beta}} \quad, \mathrm{A} \geq 0$

The conditional probability density finctions for symbols $\mathrm{z}_{1}, \mathrm{z}_{2}$,

$\mathrm{z}_{\mathrm{M}}$ remain same as in case of

Rayleigh fading. However the probability density function of the branch output signals which are obtained through averaging the conditional probabilities are given as:

$$
\begin{aligned}
& \mathrm{p}_{\mathrm{z}_{1}}\left(\mathrm{z}_{1}\right)=\int_{0}^{\infty} \int_{-\pi}^{\pi} \frac{1}{\sigma \sqrt{2 \pi}} \mathrm{e}^{-\frac{\left(\mathrm{z}_{1}-\mathrm{A}-\mathrm{A}_{1} \cos \left(\theta_{1}\right)\right)^{2}}{2 \sigma^{2}}} . \\
& \frac{\beta}{\Omega} \cdot(\mathrm{A} / \Omega)^{\beta-1} \cdot \mathrm{e}^{(-\mathrm{A} / \Omega)^{\beta}} \mathrm{dA} \frac{1}{2 \pi} \mathrm{d} \theta_{1} \ldots(18) \\
& \mathrm{p}_{\mathrm{z}_{2}}\left(\mathrm{z}_{2}\right)=\int_{0}^{\infty} \int_{-\pi}^{\pi} \frac{1}{\sigma \sqrt{2 \pi}} \mathrm{e}^{-\frac{\left(\mathrm{z}_{2}-\mathrm{A}_{2} \cos \left(\theta_{2}\right)\right)^{2}}{2 \sigma^{2}}} \cdot \\
& \frac{\beta}{\Omega} \cdot(\mathrm{A} / \Omega)^{\beta-1} \cdot \mathrm{e}^{(-\mathrm{A} / \Omega)^{\beta}} \mathrm{dA} \frac{1}{2 \pi} \mathrm{d} \theta_{2} \ldots(19) \\
& \cdots \cdots \\
& \mathrm{p}_{\mathrm{z}_{\mathrm{k}}}\left(\mathrm{z}_{\mathrm{k}}\right)=\int_{0}^{\infty} \int_{-\pi}^{\pi} \frac{1}{\sigma \sqrt{2 \pi}} \mathrm{e}^{-\frac{\left(\mathrm{z}_{\mathrm{k}}-\mathrm{A}_{\mathrm{k}} \cos \left(\theta_{\mathrm{k}}\right)\right)^{2}}{2 \sigma^{2}}} . \\
& \cdot \frac{\beta}{\Omega} \cdot(\mathrm{A} / \Omega)^{\beta-1} \cdot \mathrm{e}^{(-\mathrm{A} / \Omega)^{\beta}} \mathrm{dA} \frac{1}{2 \pi} \mathrm{d} \theta_{\mathrm{k}} \ldots(20)
\end{aligned}
$$

The cumulative distribution functions of the output signals $\mathrm{z}_{1}, \mathrm{z}_{2} \ldots \ldots \ldots \mathrm{z}_{\mathrm{M}}$ are given as:

$$
\begin{aligned}
& \mathrm{F}_{\mathrm{z}_{1}}\left(\mathrm{z}_{1}\right)=\int_{-\infty}^{\mathrm{z}_{1}} \int_{0}^{\infty} \int_{-\pi}^{\pi} \frac{1}{\sigma \sqrt{2 \pi}} \mathrm{e}^{-\frac{\left(\mathrm{z}_{1}-\mathrm{A}-\mathrm{A}_{1} \cos \left(\theta_{1}\right)\right)^{2}}{2 \sigma^{2}}} . \\
& \frac{\beta}{\Omega} \cdot(\mathrm{A} / \Omega)^{\beta-1} \cdot \mathrm{e}^{(-\mathrm{A} / \Omega)^{\beta}} \mathrm{dA} \frac{1}{2 \pi} \mathrm{d} \theta_{1} \mathrm{~d} \mathrm{z}_{1} \quad \ldots(21) \\
& \mathrm{F}_{\mathrm{z}_{2}}\left(\mathrm{z}_{2}\right)=\int_{-\infty}^{\mathrm{z}_{2}} \int_{0}^{\infty} \int_{-\pi}^{\pi} \frac{1}{\sigma \sqrt{2 \pi}} \mathrm{e}^{-\frac{\left(\mathrm{z}_{2}-\mathrm{A}_{2} \cos \left(\theta_{2}\right)\right)^{2}}{2 \sigma^{2}}} . \\
& \frac{\beta}{\Omega} \cdot(\mathrm{A} / \Omega)^{\beta-1} \cdot \mathrm{e}^{(-\mathrm{A} / \Omega)^{\beta}} \mathrm{dA} \frac{1}{2 \pi} \mathrm{d} \theta_{1} \mathrm{~d} \mathrm{z}_{2} \quad \ldots(22) \\
& \ldots . . \\
& \mathrm{F}_{\mathrm{z}_{\mathrm{k}}}\left(\mathrm{z}_{\mathrm{k}}\right)=\int_{-\infty}^{\mathrm{z}_{2}} \int_{0}^{\infty} \int_{-\pi}^{\pi} \frac{1}{\sigma \sqrt{2 \pi}} \mathrm{e}^{-\frac{\left(\mathrm{z}_{\mathrm{k}}-\mathrm{A}_{\mathrm{k}} \cos \left(\theta_{\mathrm{k}}\right)\right)^{2}}{2 \sigma^{2}}} . \\
& \frac{\beta}{\Omega} \cdot(\mathrm{A} / \Omega)^{\beta-1} \cdot \mathrm{e}^{(-\mathrm{A} / \Omega)^{\beta}} \mathrm{dA} \frac{1}{2 \pi} \mathrm{d} \theta_{\mathrm{k}} \mathrm{d} \mathrm{z}_{\mathrm{k}} \ldots(23)
\end{aligned}
$$


The probability density function of the output signal and the joint probability density function of the output and its derivative can be obtained from the equations specified in the Rayleigh fading model.

\subsection{Nakagami Fading}

In this case we would consider the impulse interference given as:

$i(t)=\sum_{i=1}^{M}\left(A_{i} \cos (\omega i t+\theta i)\right)$

Now, in this case the conditional probability density functions would now be given as:

$\mathrm{p}_{\mathrm{z}_{1} / \mathrm{A}, \theta_{1}}\left(\mathrm{z}_{1}\right)=\frac{1}{\sigma \sqrt{2 \pi}} \mathrm{e}^{-\frac{\left(\mathrm{z}_{1}-\mathrm{A}-\left(\mathrm{A}_{1}+\mathrm{cn}\right) \cos \left(\theta_{1}\right)\right)^{2}}{2 \sigma^{2}}}$

Here $\sigma$ denotes the standard deviation.

$\mathrm{p}_{\mathrm{z}_{2} / \mathrm{A}, \theta_{2}}\left(\mathrm{z}_{2}\right)=\frac{1}{\sigma \sqrt{2 \pi}} \mathrm{e}^{-\frac{\left(\mathrm{z}_{2}-\left(\mathrm{A}_{2}+\mathrm{cn}\right) \cos \left(\theta_{2}\right)\right)^{2} \text { 西 }}{2 \sigma^{2}}}$

$\mathrm{p}_{\mathrm{z}_{\mathrm{k}} / \mathrm{A}, \theta_{\mathrm{k}}}\left(\mathrm{z}_{\mathrm{k}}\right)=\frac{1}{\sigma \sqrt{2 \pi}} \mathrm{e}^{-\frac{\left(\mathrm{z}_{\mathrm{k}}-\left(\mathrm{A}_{\mathrm{k}}+\mathrm{cn}\right) \cos \left(\theta_{\mathrm{k}}\right)\right)^{2}}{2 \sigma^{2}}}$

Again we would average the equations (24) to (26) to get the probability density functions of the branch output signals. Therefore,

$\mathrm{p}_{\mathrm{z}_{1}}\left(\mathrm{z}_{1}\right)=\int_{0}^{\infty} \int_{-\pi}^{\pi} \frac{1}{\sigma \sqrt{2 \pi}} \mathrm{e}^{-\frac{\left(\mathrm{z}_{1}-\mathrm{A}-\left(\mathrm{A}_{1}+\mathrm{cn}\right) \cos \left(\theta_{1}\right)\right)^{2}}{2 \sigma^{2}}}$.

$\cdot \sum_{n=0}^{\infty} \frac{\lambda^{\mathrm{n}}}{\mathrm{n} !} \mathrm{e}^{-\lambda} \cdot \frac{2}{\Gamma\left(\mathrm{m}_{1}\right)} \cdot \frac{\mathrm{m}_{1}}{\Omega_{1}} \cdot \mathrm{A}^{2 \mathrm{~m}_{1}-1} \mathrm{e}^{\left(\mathrm{m}_{1} / \Omega_{1}\right) \cdot \mathrm{A}^{2}} \mathrm{dA} \cdot \frac{1}{2 \pi} \mathrm{d} \theta_{1}$

$\mathrm{p}_{\mathrm{z}_{2}}\left(\mathrm{z}_{2}\right)=\int_{0}^{\infty} \int_{-\pi}^{\pi} \frac{1}{\sigma \sqrt{2 \pi}} \mathrm{e}^{-\frac{\left(\mathrm{z}_{2}-\left(\mathrm{A}_{2}+\mathrm{cn}\right) \cos \left(\theta_{2}\right)\right)^{2}}{2 \sigma^{2}}}$.

$\cdot \sum_{n=0}^{\infty} \frac{\lambda^{n}}{n !} e^{-\lambda} \cdot \frac{2}{\Gamma\left(m_{2}\right)} \cdot \frac{m_{2}}{\Omega_{2}} \cdot A^{2 m_{2}-1} e^{\left(m_{2} / \Omega_{2}\right) \cdot A^{2}} d A \cdot \frac{1}{2 \pi} d \theta_{2} .$.

$\mathrm{p}_{\mathrm{z}_{\mathrm{k}}}\left(\mathrm{z}_{\mathrm{k}}\right)=\int_{0}^{\infty} \int_{-\pi}^{\pi} \frac{1}{\sigma \sqrt{2 \pi}} \mathrm{e}^{-\frac{\left(\mathrm{z}_{\mathrm{k}}-\left(\mathrm{A}_{\mathrm{k}}+\mathrm{cn}\right) \cos \left(\theta_{\mathrm{k}}\right)\right)^{2}}{2 \sigma^{2}}}$.

$\cdot \sum_{n=0}^{\infty} \frac{\lambda^{n}}{n !} e^{-\lambda} \cdot \frac{2}{\Gamma\left(m_{k}\right)} \cdot \frac{m_{k}}{\Omega_{k}} \cdot A^{2 m_{k}-1} e^{\left(m_{k} / \Omega_{k}\right) \cdot A^{2}} d A \cdot \frac{1}{2 \pi} d \theta_{k} \cdot$

And, the cumulative distribution functions are :

$\mathrm{F}_{\mathrm{z}_{1}}\left(\mathrm{z}_{1}\right)=\int_{-\infty}^{\mathrm{z}} \int_{0}^{\infty} \int_{-\pi}^{\pi} \frac{1}{\sigma \sqrt{2 \pi}} \mathrm{e}^{-\frac{\left(\mathrm{z}_{1}-\mathrm{A}-\left(\mathrm{A}_{1}+\mathrm{cn}\right) \cos \left(\theta_{1}\right)\right)^{2}}{2 \sigma^{2}}}$.

$\cdot \sum_{n=0}^{\infty} \frac{\lambda^{\mathrm{n}}}{\mathrm{n} !} \mathrm{e}^{-\lambda} \cdot \frac{2}{\Gamma\left(\mathrm{m}_{1}\right)} \cdot \frac{\mathrm{m}_{1}}{\Omega_{1}} \cdot \mathrm{A}^{2 \mathrm{~m}_{1}-1} \mathrm{e}^{\left(\mathrm{m}_{1} / \Omega_{1}\right) \cdot \mathrm{A}^{2}} \mathrm{dA} \cdot \frac{1}{2 \pi} \mathrm{d} \theta_{1} \mathrm{dz} .$.

$\mathrm{F}_{\mathrm{z}_{2}}\left(\mathrm{z}_{2}\right)=\int_{-\infty}^{\mathrm{z}} \int_{0}^{\infty} \int_{-\pi}^{\pi} \frac{1}{\sigma \sqrt{2 \pi}} \mathrm{e}^{-\frac{\left(\mathrm{z}_{2}-\left(\mathrm{A}_{2}+\mathrm{cn}\right) \cos \left(\theta_{2}\right)\right)^{2}}{2 \sigma^{2}}}$.

$\cdot \sum_{n=0}^{\infty} \frac{\lambda^{n}}{n !} \mathrm{e}^{-\lambda} \cdot \frac{2}{\Gamma\left(m_{2}\right)} \cdot \frac{m_{2}}{\Omega_{2}} \cdot A^{2 m_{2}-1} e^{\left(m_{2} / \Omega_{2}\right) \cdot A^{2}} d A \cdot \frac{1}{2 \pi} d \theta_{2} d z$ 


$$
\begin{aligned}
& F_{z_{k}}\left(z_{k}\right)=\int_{-\infty}^{z} \int_{0}^{\infty} \int_{-\pi}^{\pi} \frac{1}{\sigma \sqrt{2 \pi}} e^{-\frac{\left(z_{k}-\left(A_{k}+c n\right) \cos \left(\theta_{k}\right)\right)^{2}}{2 \sigma^{2}}} \cdot \\
& \sum_{n=0}^{\infty} \frac{\lambda^{n}}{n !} e^{-\lambda} \cdot \frac{2}{\Gamma\left(m_{k}\right)} \cdot \frac{m_{k}}{\Omega_{k}} \cdot A^{2 m_{k}-1} e^{\left(m_{k} / \Omega_{k}\right) \cdot A^{2}} d A \cdot \frac{1}{2 \pi} d \theta_{k} d z . .
\end{aligned}
$$

The probability density function of M-ary FSK receiver output during the taken hypothesis is given by:

$\mathrm{p}_{\mathrm{z}}(\mathrm{z})=\sum_{\mathrm{i}=1}^{\mathrm{M}} \mathrm{p}_{\mathrm{i}}(\mathrm{z}) \cdot \prod_{\substack{\mathrm{j}=1 \\ \mathrm{j} \neq \mathrm{i}}}^{\mathrm{M}} \mathrm{F}_{\mathrm{j}}(\mathrm{z})$

Now, we can evaluate how the presence of different types of fading at the receiver input would affect the output.

\section{Computer Simulation Results}

We are considering the FSK receiver for $M=2$ since it is easy to implement. The probability density function in this case is given as:

$\mathrm{p}_{\mathrm{z}}\left(\mathrm{z}_{1}\right)=\mathrm{p}_{\mathrm{z}_{11}}\left(\mathrm{z}_{1}\right) \cdot \mathrm{F}_{\mathrm{z}_{12}}\left(\mathrm{z}_{1}\right)+\mathrm{p}_{\mathrm{z}_{12}}\left(\mathrm{z}_{1}\right) \cdot \mathrm{F}_{\mathrm{z}_{11}}\left(\mathrm{z}_{1}\right)$

First of all, we would consider the Rayleigh fading model. The computer simulation results have been given in the figure 2 . We could see that how by changing the value of $\sigma$, the probability density function varies

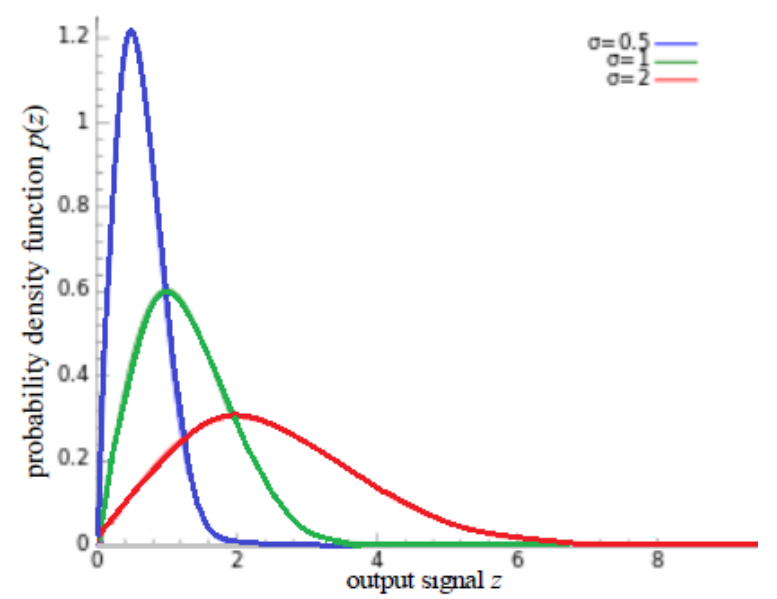

Figure: 2

We now consider Weibull fading model. In this case we have to see the effect on pdf due to different parameters. Taking $\Omega$ and $\beta$ as constant and varying the value of variance $\sigma$, we get the graph shown in figure 4 when $\mathrm{A}_{\mathrm{i}}$ is taken as 2 .

If we take $\beta$ as varying parameter then in that case we would get the graph shown in figure 5 . In this graph, the value of $\Omega$ and $\sigma$ are kept constant and $A_{i}$ is taken as 4 .

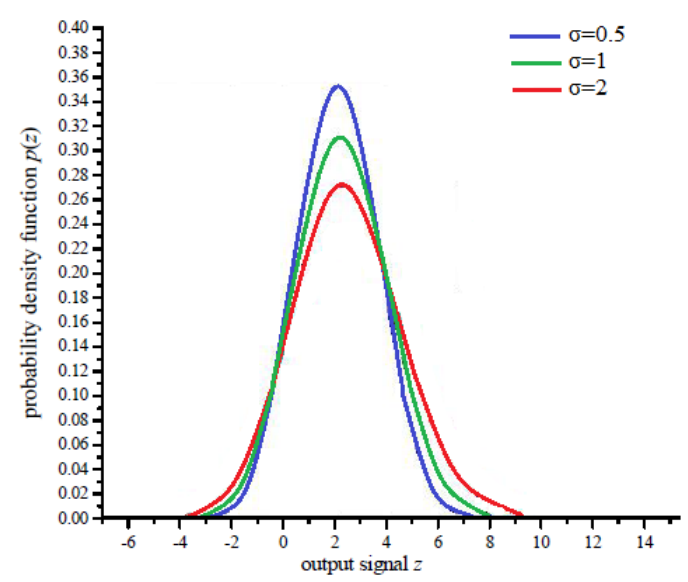

Figure:3 


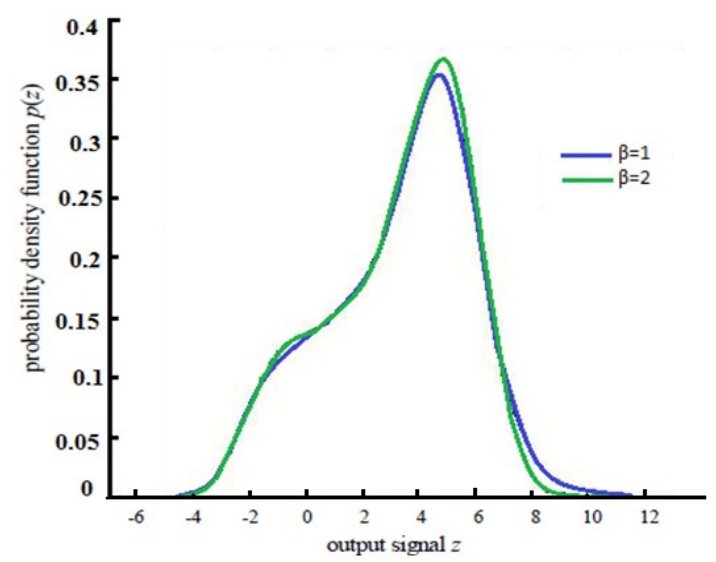

Figure: 4

Now if we vary the value of $\Omega$,and keep $\sigma, A_{i}$ and $\beta$ constant, the graph obtained is as shown in figure $6 . A_{i}$ is taken as 3:

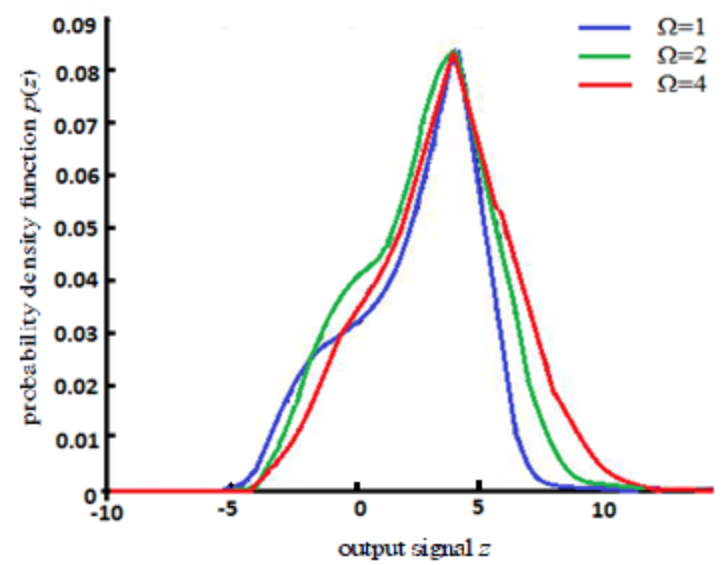

Figure:5

Now, we want to see the effect of varying $A_{i}$ on the probability density function.The other parameters are taken as $\sigma=1, \Omega=2$ and $\beta=3$. The graphical characteristics are shown in figure 6 :

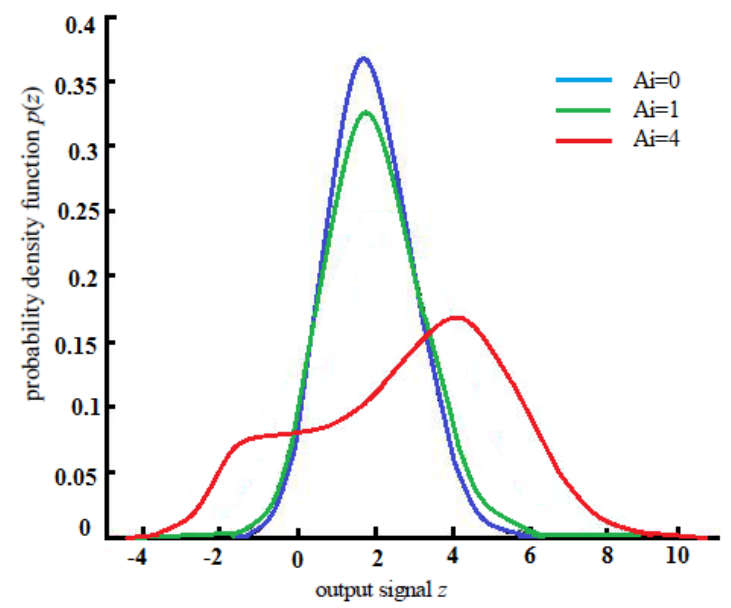

Figure: 6

Now, considering the case of Nakagami Fading. Here we would consider the variation of probability density function with change in different parameters such as average power $\Omega$,

Fading severity parameter $\mathrm{m}$, standard deviation $\sigma, \lambda$, A and $\mathrm{c}$.

First of all,considering $A=0, c=0, \sigma=1, \lambda=1$ and $\Omega=2$, we would see the variation of probability density 
function due to change in value of $\mathrm{m}$.

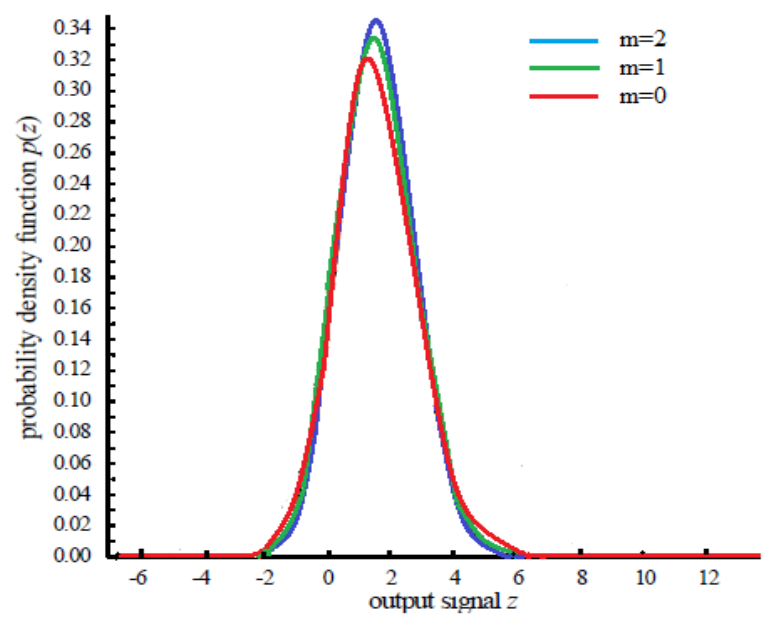

Figure: 7

Now taking the parameters $\sigma=1, \lambda=1, \mathrm{~m}=1, \mathrm{~A}_{1}=0$ and $\mathrm{c}=0$, we ploted the graph with different values of $\Omega$ as shown in figure 8:

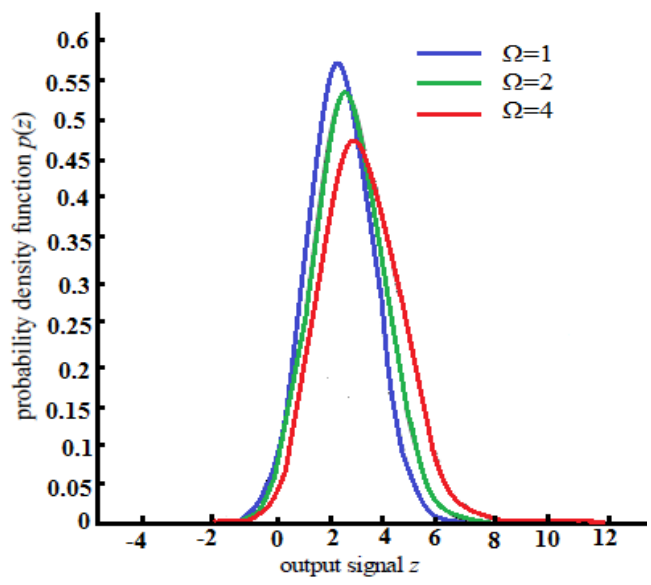

Figure:8

The next figure shown give the dependence of probability density function with the change in parameter $\lambda$. Other parameters are taken as $\sigma=1, \Omega=2, A_{i}=0$ and $m=1$. Figure 9 and Figure 10 correspond to the value $\lambda=1$ with $\mathrm{A}_{\mathrm{i}}=0$ and $\mathrm{A}_{\mathrm{i}}=4$ respectively.

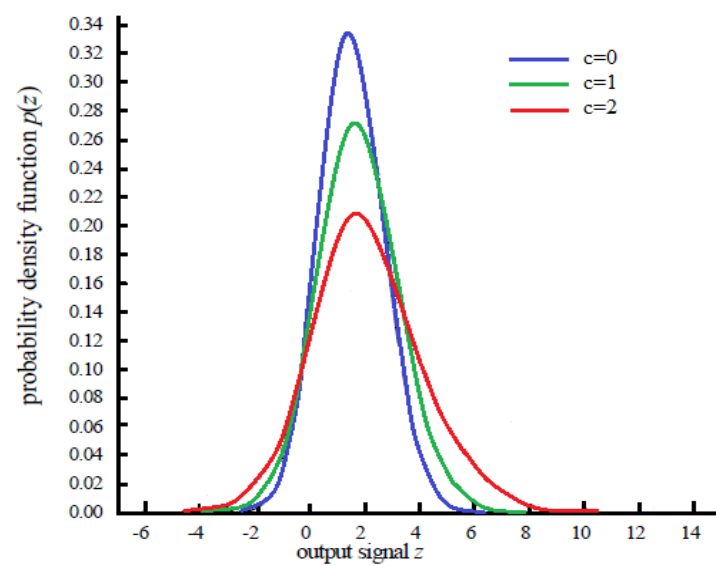

Figure:9 


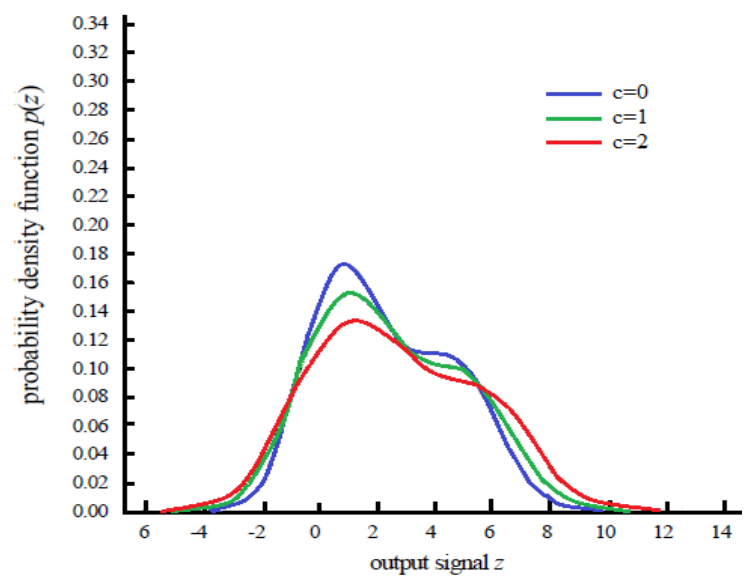

Figure :10

Now taking the value of $\lambda=0.5$,Figure 11 and Figure 12 are plotted taking the value of $A_{i}$ as 0 and 4 for figures 11 and 12 respectively.

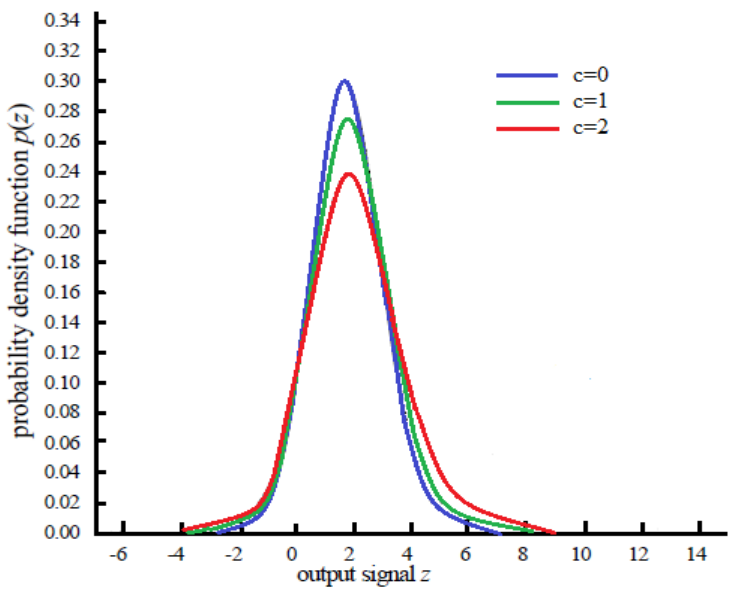

Figure:11

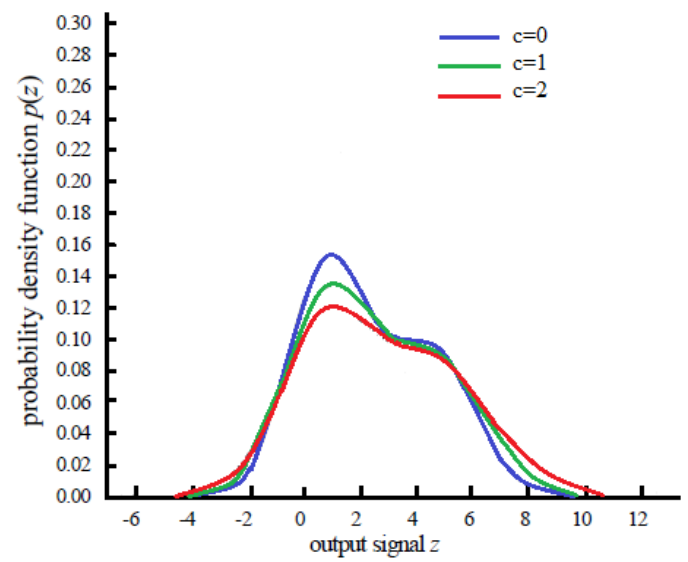

Figure:12

The probability density functions $\mathrm{p}(\mathrm{z})$ versus output signal $\mathrm{z}$, when dependence is on standard deviation $\sigma$, are given in Figures 13 and 14. For Figure 13, $\sigma=0.5, \lambda=1, \Omega=2, \mathrm{~m}=1$ and $\mathrm{A}_{\mathrm{i}}=0$ 


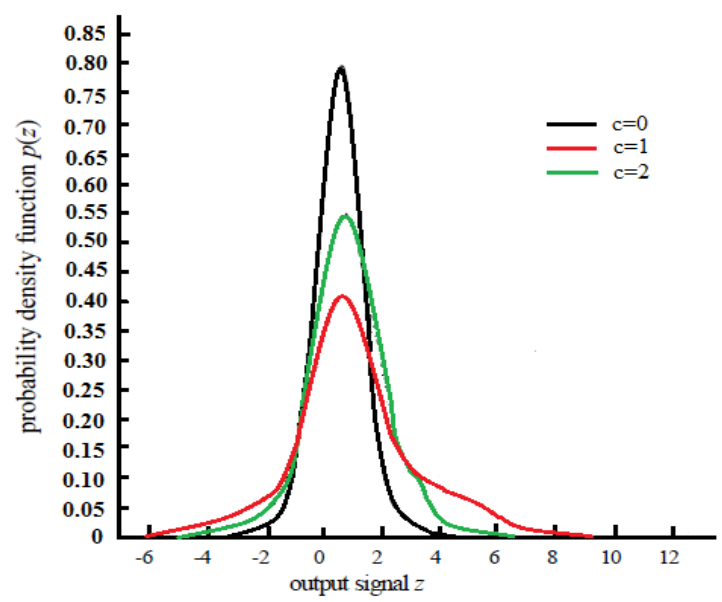

Figure:13

Now,for the figure 14,the parameters taken are $\sigma=1, \lambda=1, \Omega=2 \quad \mathrm{~A}_{\mathrm{i}}=0$ and $\mathrm{m}=1$

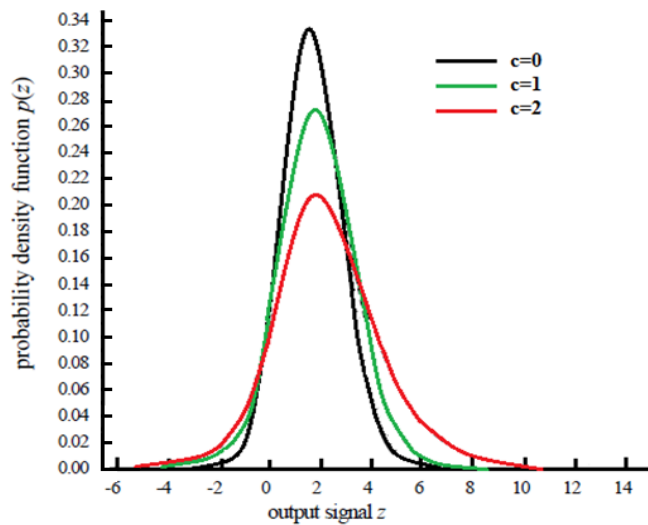

Figure :14

\section{Conclusion}

The statistical characteristics of the signal derived for the cases of different fading help us see how a particular environment have effect on the output of the system. The results obtained are of great significance since we can calculate the average level crossing rate i.e how often fading crosses some threshold or the measure of rapidity of fading, average fade duration i.e how long the signal spends below threshold with the help of joint probability density function of output and its derivative. Also,bit error probability, signal error probability of the output can be determined from the probability density function of the output in the particular form of fading.By knowing how a particular environment affect the system, we can find out ways by which we can reduce the probability of error.

\section{Acknowledgment}

I would like to thank my friend Kirti and Saloni who helped me in editing the content and suggesting me the proper books.i would also like to thank my parents who encouraged me to write this paper.

\section{References:}

[1]. J. G. Proakis, Digital Communications, 2nd ed. New York, McGraw-Hill, 1989.

[2]. K. A. Farrell and P. J. McLane, "Performance of the cross-correlator receiver for binary digital frequency modulation", IEEE Trans. Commun., Vol. 45, No 5, May 1997.

[3]. Marvin K. Simon, Mohamed-Slim Alouni, Digital Communication over Fading Channels, Second Edition, Wiley Interscience, New Jersey, 2005, pp. 586.

[4]. R. L. Bogusch, "Digital Communications in Fading Channels: Modulation and Coding," Mission Research Corp., Santa Barbara, CA, Report no. MRC-R-1043, Mar. 11, 1987.

[5]. B. Sklar, Digital Communications: Fundamentals and Applications, Englewood Cliffs, NJ: Prentice Hall, 1988.

[6]. Gorden L.Stuber, Principles of Mobile Communication, Second Edition

[7]. Yeon Kyoon Jeong, Kwang Bok Lee, "Performance analysis of wide-band M-ary FSK systems in Rayleigh fading channels", IEEE Trans. On Commun.,

[8]. H. Huynh, M. Lecours, "Impulsive Noise in Noncoherent M-ary Digital Systems", IEEE Trans. on Commun. 